\title{
Adaptação Transcultural da Escala Lúdica Pré-Escolar de Knox - Revisada para Uso na População Brasileira
}

\author{
Amanda Mota Pacciulio Sposito", Luzia Iara Pfeifer \& Jair Licio Ferreira Santos \\ Universidade de São Paulo, Ribeirão Preto, Brasil
}

\begin{abstract}
RESUMO
O brincar proporciona estímulos para o desenvolvimento motor, social, emocional, cognitivo e da linguagem da criança. O conhecimento acerca da atividade lúdica, o que inclui a avaliação do brincar, faz-se então indispensável para profissionais que atuam com crianças. Esta pesquisa objetivou traduzir e adaptar culturalmente a Escala Lúdica Pré-Escolar de Knox - Revisada para aplicação na população brasileira, bem como realizar o seu pré-teste com 18 crianças de 0 a 6 anos de idade, sem comprometimento motor, cognitivo ou sensorial, e verificar a confiabilidade do instrumento intra e interexaminadores. A autora da Escala concordou com as adaptações culturais necessárias para a versão brasileira do instrumento, aqui apresentado, e a análise estatística realizada apontou sua confiabilidade e repetibilidade.
\end{abstract}

Palavras-chave: adaptação transcultural; brincar; avaliação; criança pré-escolar.

\section{ABSTRACT \\ Cross-Cultural Adaptation of Revised Knox Preschool Play Scale for Use in Brazilian Population}

Playing provides stimulus to the physical, social, emotional, cognitive and language development of the child. The knowledge about the ludic activity, including the assessment of playing, is indispensable for professionals that work with children. This study aimed to perform the translation and cultural adaptation of the Revised Knox Preschool Play Scale to be used with the Brazilian population, as well as to carry out its pretest in 18 children ages 0 to 6 years, with no motor, cognitive or sensorial impairment, and to verify the intra and interexaminers reliability of the instrument. The author of the Scale agreed with necessary cultural adaptations for the Brazilian version of the instrument here presented and the statistical analysis pointed to its reliability, consistency, and repeatability.

Keywords: cross-cultural adaptation; play; assessment; pre-school child.

O brincar faz-se indispensável na idade pré-escolar, uma vez que facilita a compreensão da cultura, flexibilidade de pensamento, adaptação, aprendizado, resolução de problemas, integração de informações do ambiente, desenvolvimento social, cognitivo, emocional, de habilidades físicas e linguagem (Braccialli, Manzini \& Reganhan, 2004; Emmel, Oliveira \& Malfitano, 2000; Knox 2002). Contribui para a aprendizagem e o desenvolvimento infantil, uma vez que permite a ação intencional, a construção de representações mentais, a manipulação de objetos, desempenho de ações sensório-motoras e as trocas nas interações sociais (Kishimoto, 2008).
Através das brincadeiras a criança pode comunicar medo e ansiedade, adquirir um senso de controle da situação (Gariépy \& Howe, 2003), testar e desenvolver suas habilidades, além de ser estimulada em sua criatividade, iniciativa e autoconfiança (Pedrosa, Monteiro, Lins, Pedrosa \& Melo, 2007), pois brincado a criança encontra-se em estado de busca, de descoberta, indagação, escolha, criação e recriação (Pereira, 2005). O brincar envolve a motivação intrínseca da criança na busca do prazer através da ação, priorizando os meios (o durante) em detrimento do fim (resultado) da atividade lúdica (Rezende, 2005). 
Sendo o brincar essencial ao desenvolvimento infantil, sua avaliação pode ser considerada de extrema importância para profissionais que trabalham com crianças. De acordo com Rezende (2005), autores como Piaget (1962) e Parten (1932) descreveram as atividades recreativas em um critério evolutivo, relacionando-as à faixa etária da criança, o que permitiu o desenvolvimento posterior de diversos instrumentos de avaliação do brincar.

Os instrumentos padronizados para uso junto à população infantil, incluindo aqueles que avaliam o brincar, podem ser utilizados para determinar a elegibilidade da criança para o serviço terapêutico, monitorar progressos obtidos ao longo do processo de tratamento e auxiliar nas decisões acerca da intervenção mais apropriada e efetiva para o caso, além de possibilitarem uma linguagem comum entre os profissionais e facilitarem a comunicação destes com a família (Richardson, 2001).

Em revisão bibliográfica realizada por Pfeifer e Cruz (2008) foram localizadas na literatura internacional seis avaliações do comportamento lúdico, utilizadas por terapeutas ocupacionais, e que apresentam evidências para a prática profissional na clínica e na pesquisa: Histórico Lúdico (Takata, 1974); Avaliação Transdisciplinar baseada no Brincar (Linder, 2001); Teste de Entretenimento (Bundy, 2000); Avaliação do Comportamento Lúdico (Ferland, 2006); Avaliação do Brincar de Faz-de-conta Iniciado pela Criança (Stagnitti, 2007) e Escala Lúdica Pré-Escolar de Knox Revisada (Knox, 2000). Duas destas avaliações já passaram pelo processo de adaptação transcultural para serem utilizadas para a população brasileira, sendo elas a Avaliação do Comportamento Lúdico (Sant'Anna, Blascovi-Assis \& Magalhães, 2008) e Avaliação do Brincar de Faz-de-conta Iniciado pela Criança (Pfeifer, Queiroz, Santos \& Stagnitti, 2011).

Especificamente no que diz respeito à Escala Lúdica Pré-Escolar de Knox, esta foi desenvolvida em 1968, pela terapeuta ocupacional norte-americana Susan Knox e foi denominada inicialmente apenas como Escala Lúdica. Bledsoe e Shepherd (1982) revisaram o instrumento propondo pequenas alterações em seu conteúdo, o renomearam como Escala Lúdica Pré-Escolar e verificaram sua fidedignidade e validade, a qual foi, posteriormente, confirmada em estudo de Harrison e Kielhofner (1986).

Após o exame da fidedignidade e da utilidade desta Escala, assim como de suas limitações, a autora decidiu realizar algumas alterações e então propôs a Escala Lúdica Pré-Escolar de Knox - Revisada. Este ins- trumento consiste em uma ferramenta de avaliação, baseada em observação, projetada para fornecer uma descrição evolutiva do comportamento lúdico típico de crianças pré-escolares, em períodos de seis meses do zero aos três anos de idade e em períodos anuais até os seis anos de idade (Knox, 2000). São apresentadas, em cada faixa etária, as ações que as crianças desempenham normalmente, as quais são divididas em quatro dimensões: domínio espacial, domínio material, "faz de conta" ou jogo simbólico e participação (Knox, 2000, 2002).

O domínio espacial é a maneira como a criança aprende a movimentar seu corpo e a interagir com o mundo ao seu redor (Knox, 2000, 2002). Abrange os seguintes fatores: a coordenação motora grossa, referente a atividades recreativas que envolvem todo o corpo; e o interesse, que são as escolhas das atividades recreativas (Knox, 2000).

O domínio material é a maneira como a criança manipula os objetos (Knox, 2000, 2002) e engloba: a manipulação, referente a atividades recreativas que envolvem a motricidade fina; a construção, que diz respeito à combinação de objetos e confecção de produtos; o objetivo da atividade e a atenção dispensada à recreação (Knox, 2000).

O "faz de conta" ou jogo simbólico é a maneira pela qual a criança aprende sobre o mundo através da imitação e da capacidade de compreender e separar a realidade da fantasia (Knox, 2000, 2002). Abrange os seguintes fatores: a imitação que é a reprodução dos comportamentos de seu ambiente imediato e a dramatização que consiste na introdução de novidades e desempenho de papéis (Knox, 2000).

Finalmente, a participação está relacionada à quantidade e à maneira como a interação social ocorre (Knox, 2000, 2002), englobando o tipo de interação durante a atividade recreativa; a cooperação, que se refere à capacidade de lidar com os outros na atividade recreativa; o humor, que diz respeito ao entendimento e expressão de palavras ou episódios humorísticos e a linguagem com os outros durante a recreação (Knox, 2000).

Em revisão de literatura, foram identificados diversos estudos que utilizaram a Escala Lúdica PréEscolar, assim como sua versão revisada, para avaliar o desenvolvimento de crianças que possuíam diagnósticos de: distúrbios de integração sensorial (Bundy, 1989, Clifford \& Bundy, 1989); artrite reumatoide juvenil (Morrison, Bundy \& Fisher, 1991); autismo (Restall \& Magill-Evans, 1994); deficit intelectual (Messier, Ferland \& Majnemer, 2008) e atrasos da 
fala e da linguagem (Sheperd, Brollier \& Dandrow, 1994). Foi também utilizada para avaliar crianças que sofreram abuso sexual (Howard, 1986); que se encontravam em programa de intervenção precoce devido a alterações motoras e sensoriais (Schaaf \& Mulrooney, 1989); hospitalizadas (Kielhofner, Barris, Bauer, Shoestock \& Walker, 1983) e procedentes de classes econômicas baixa e média (von Zuben, Crist \& Mayberry, 1991), assim como para avaliar os progressos obtidos nos atendimentos terapêutico ocupacionais de crianças que apresentavam dificuldades no brincar (O’Brien e cols., 2000).

A Escala Lúdica Pré-Escolar foi considerada, em todas as pesquisas, válida para avaliar o desenvolvimento infantil e indicar quais as áreas que se encontravam com atrasos e necessitavam de intervenção. Estes estudos mostraram a utilidade da Escala em diferenciar as capacidades lúdicas em várias populações, apontaram a natureza individual do brincar e da habilidade da criança em superar algumas incapacidades (Knox, 2000).

Apesar da ampla utilização desta Escala em pesquisas acadêmicas e na prática clínica norte-americana, este instrumento não havia sido ainda traduzido, adaptado e validado para uso na população brasileira. A Organização Mundial da Saúde recomenda a tradução e adaptação cultural dos instrumentos de avaliação já existentes, em detrimento da criação de novos testes. Este processo favorece a comunicação entre diferentes pesquisadores e a comparação dos dados obtidos em nível internacional, além de ser considerado mais rápido e com menor custo que o desenvolvimento de novos instrumentos (Prado, Braga, Magalhães \& Wilson, 2007).

A adaptação de um instrumento, para ser utilizado em um novo país, ou nova cultura (ainda que dentro do mesmo país), necessita de um método único para garantir equivalência entre as versões originais e adaptadas da avaliação. Já é reconhecido que, se a escala será utilizada em culturas diferentes, seus itens não só precisam estar linguisticamente bem traduzidos como também é necessário que sejam submetidos a uma adaptação cultural, com o objetivo de manter a validade do conteúdo do instrumento (Beaton, Bombardier, Guillemin \& Ferraz, 2000; Sant'Anna, 2006). O processo que enfoca tanto a linguagem (tradução), quanto à adaptação cultural de um instrumento de avaliação é denominado adaptação transcultural.

O presente estudo tem como objetivo apresentar a versão adaptada culturalmente da Escala Lúdica PréEscolar de Knox - Revisada, para uso junto à população brasileira.

\section{MÉTODO}

\section{Tradução e Adaptação Transcultural}

A partir da Escala Lúdica Pré-Escolar de Knox Revisada original, em inglês, foi realizada a adaptação transcultural, que teve por base as instruções de Beaton e cols. (2000) e constituiu-se de seis estágios:

Estágio I. Dois tradutores (incluindo a primeira autora deste artigo), fluentes na língua inglesa e que possuem diferentes perfis e formações profissionais, traduziram o instrumento do inglês para o português.

Estágio II. Os dois tradutores reuniram-se para uma discussão, a qual objetivou sintetizar os conteúdos de ambas as traduções em uma única, denominada tradução comum.

Estágio III. Utilizando a tradução comum e sem conhecer a versão original, dois outros tradutores, os quais têm como língua materna o inglês e não possuem conhecimentos acadêmicos acerca da área avaliada no instrumento a ser traduzido, realizaram a tradução do português para o inglês novamente, como meio de checar a validade da nova versão.

Estágio $I V$. Foi composto um comitê com todas as pessoas envolvidas no processo de tradução, o qual teve como objetivo revisar todas as traduções, resolver qualquer possível discrepância entre elas e reunir todas as versões do instrumento em uma única versão final.

Estágio $V$. A versão final foi submetida à autora da Escala Lúdica Pré-Escolar, para verificar se esta a aceitava e concordava com as adaptações, permitindo sua utilização no Brasil.

Estágio VI. Foi realizado o pré-teste da versão brasileira do instrumento.

\section{PRÉ-TESTE}

\section{Participantes}

Participaram do pré-teste 18 crianças sem comprometimento motor, cognitivo e sensorial; sem distinção de sexo; divididas em nove grupos (de 2 crianças cada) nas seguintes faixas etárias: 0 a 6 meses, 6 a 12 meses, 12 a 18 meses, 18 a 24 meses, 24 a 30 meses, 30 a 36 meses, 36 a 48 meses, 48 a 60 meses e 60 a 72 meses; provenientes de duas escolas de educação infantil, as quais possuíam, também, berçário em suas dependências. 


\section{Coleta dos Dados}

As crianças foram designadas por um funcionário da escola, aleatoriamente, possibilitando assim uma análise "cega" dos participantes. Após a seleção, foram realizadas observações do brincar livre dessas crianças, sendo que todas as observações foram filmadas pela primeira autora deste estudo, permitindo posterior análise.

Os bebês de 0 a 12 meses foram filmados individualmente, durante 30 minutos em um local fechado, porém amplo, sendo que em algum momento da filmagem o bebê estava em interação com a cuidadora responsável (da própria instituição). As crianças de 12 a 72 meses, foram observadas em duplas, possibilitando assim o brincar com pares; essas filmagens foram realizadas em dois ambientes distintos: 30 minutos em uma sala fechada e 30 minutos ao ar livre, possibilitando o brincar que envolve o "faz de conta", o domínio material, o domínio espacial e a participação.

\section{Análise dos Dados}

Como forma de quantificar o comportamento observado nas filmagens, permitindo a posterior análise estatística do desempenho das crianças, bem como a realização dos testes de confiabilidade deste estudo, cada um dos tópicos presentes nas quatro dimensões da escala foi separado como um item a ser pontuado. Utilizou-se a pontuação proposta por Pfeifer (2006), a qual determina: 2 pontos - se a criança apresenta seguramente o comportamento esperado ou realiza de forma satisfatória a tarefa determinada; 1 ponto - se a criança não apresenta seguramente o comportamento esperado ou realiza de forma hesitante a tarefa determinada; 0 pontos - se o comportamento esperado ou a tarefa determinada não puderam ser observados por falta de condições e recursos materiais, do ambiente e/ou humanos; -1 ponto - se a criança não apresentou o comportamento esperado ou não realizou a tarefa determinada, mesmo tendo oportunidade.

Duas examinadoras assistiram às filmagens, em dois momentos distintos, permitindo assim análises intra e interexaminadores. As examinadoras assistiram separadamente às filmagens, e foi respeitado um intervalo de 5 meses entre a primeira e a segunda análise de cada uma delas.

Para verificação da confiabilidade do instrumento, intraexaminador e interexaminadores, foram realizadas análises estatísticas utilizando-se o Coeficiente de Correlação de Spearman, com os respectivos testes de significância (Siegel \& Castellan, 2006).

\section{RESULTADOS}

Durante a realização da adaptação transcultural, apenas não foram encontradas brincadeiras equivalentes no Brasil para pulls apart pop beads e strings beads, brincadeiras estas tradicionais nos Estados Unidos, que utilizam como materiais contas e fios. Nesse caso, foi realizada uma adaptação para as brincadeiras de colocar macarrões em barbante - utilizada com frequência nas escolas brasileiras de educação infantil e de puxar argolas (contas, macarrão, etc.) em um cordão, pois exigem as mesmas habilidades motoras e cognitivas que as brincadeiras citadas na Escala original.

Todos os itens da escala foram mantidos e, após todo o processo de tradução e adaptação transcultural, a versão final foi encaminhada para a autora, que concordou com as pequenas modificações realizadas, confirmando a equivalência entre as brincadeiras.

A versão brasileira da Escala, traduzida e adaptada culturalmente, será apresentada nas Tabelas de 1 a 9 a seguir, de acordo com a subdivisão em faixas etárias. 
Tabela 1

Versão Brasileira da Escala Lúdica Pré-Escolar de Knox - Revisada para Avaliação de Crianças de 0 a 6 Meses de Idade

\begin{tabular}{|c|c|c|c|c|}
\hline \multirow[b]{2}{*}{$\begin{array}{l}\text { Domínio } \\
\text { Espacial }\end{array}$} & \multicolumn{2}{|c|}{ Coordenação Motora Grossa } & \multicolumn{2}{|c|}{ Interesse } \\
\hline & \multicolumn{2}{|c|}{$\begin{array}{l}\text { Golpeia ("corta" o ar); estende os braços para alcançar objetos; } \\
\text { brinca com mãos e pés; move-se buscando sensações } \\
\text { agradáveis. }\end{array}$} & \multicolumn{2}{|c|}{$\begin{array}{l}\text { Por pessoas; contempla faces; segue movimentos; } \\
\text { responde a vozes e sons; explora a si próprio e objetos } \\
\text { dentro do seu alcance. }\end{array}$} \\
\hline & Manipulação & Construção & Objetivo & Atenção \\
\hline $\begin{array}{l}\text { Domínio } \\
\text { Material }\end{array}$ & $\begin{array}{l}\text { Tateia; leva brinquedos à } \\
\text { Boca; bate o objeto } \\
\text { (pancadas); chacoalha. }\end{array}$ & Coloca dois objetos juntos. & $\begin{array}{l}\text { Sensação - usa materiais } \\
\text { para ver, tocar, ouvir, } \\
\text { cheirar, morder. }\end{array}$ & $\begin{array}{l}\text { Segue com os olhos } \\
\text { objetos em movimento; } \\
\text { mantém } 3 \text { a } 5 \text { segundos } \\
\text { de atenção. }\end{array}$ \\
\hline \multirow{2}{*}{$\begin{array}{l}\text { "Faz de conta" I } \\
\text { Jogo Simbólico }\end{array}$} & \multicolumn{2}{|c|}{ Imitação } & \multicolumn{2}{|c|}{ Dramatização } \\
\hline & \multicolumn{2}{|c|}{$\begin{array}{l}\text { De expressões faciais e movimentos físicos observados (ex.: } \\
\text { sorridente, acompanha palmas); imita a vocalização. }\end{array}$} & \multicolumn{2}{|l|}{ Não evidente. } \\
\hline & Tipo & Cooperação & Humor & Linguagem \\
\hline Participação & $\begin{array}{l}\text { Solitário; não há tentativa de } \\
\text { interagir com outras } \\
\text { crianças; diverte-se sendo } \\
\text { balançado ou erguido no ar. }\end{array}$ & $\begin{array}{l}\text { Exige atenção pessoal; se entre- } \\
\text { ga facilmente e interage com o } \\
\text { cuidador (cócegas, brincadeiras } \\
\text { em que o adulto esconde seu } \\
\text { rosto e depois reaparece surpre- } \\
\text { endendo o bebê - "cúti"). }\end{array}$ & $\begin{array}{l}\text { Atende } \\
\text { sons de }\end{array}$ & $\begin{array}{l}\text { sons e vozes; balbucia; } \\
\text { sadas. }\end{array}$ \\
\hline
\end{tabular}

Tabela 2

Versão Brasileira da Escala Lúdica Pré-Escolar de Knox - Revisada para Avaliação de Crianças de 6 a 12 Meses de Idade

\begin{tabular}{|c|c|c|c|c|}
\hline \multirow[b]{2}{*}{$\begin{array}{l}\text { Domínio } \\
\text { Espacial }\end{array}$} & \multicolumn{2}{|c|}{ Coordenação Motora Grossa } & \multicolumn{2}{|r|}{ Interesse } \\
\hline & \multicolumn{2}{|c|}{$\begin{array}{l}\text { Estende os braços para alcançar objetos em decúbito } \\
\text { ventral; rasteja; engatinha; senta com equilíbrio; é capaz } \\
\text { de brincar com brinquedos enquanto está sentado; apoia } \\
\text { para ficar em pé e começa a andar. }\end{array}$} & \multicolumn{2}{|c|}{$\begin{array}{l}\text { Segue objetos até eles desaparecerem; antecipa movimentos; } \\
\text { realiza movimentos visando um objetivo direto. }\end{array}$} \\
\hline \multirow[b]{2}{*}{$\begin{array}{l}\text { Domínio } \\
\text { Material }\end{array}$} & Manipulação & Construção & Objetivo & Atenção \\
\hline & $\begin{array}{l}\text { Puxa; gira; empurra; } \\
\text { rasga; raspa; deixa cair; } \\
\text { pega pequenos objetos. }\end{array}$ & $\begin{array}{l}\text { Agrupa objetos relaciona- } \\
\text { dos; coloca objetos em } \\
\text { recipientes. }\end{array}$ & $\begin{array}{l}\text { Ações para produzir } \\
\text { efeitos; brinquedos de } \\
\text { ação e reação. }\end{array}$ & $\begin{array}{l}15 \text { segundos para objetos } \\
\text { detalhados; } 30 \text { segundos para } \\
\text { brinquedos com estímulos visuais. }\end{array}$ \\
\hline \multirow[b]{2}{*}{$\begin{array}{l}\text { "Faz de conta" I } \\
\text { Jogo Simbólico }\end{array}$} & \multicolumn{2}{|c|}{ Imitação } & \multicolumn{2}{|r|}{ Dramatização } \\
\hline & \multicolumn{2}{|c|}{$\begin{array}{l}\text { Imita ações observadas, emoções, sons e gestos que não } \\
\text { fazem parte de um repertório; imita modelos de atividades } \\
\text { familiares. }\end{array}$} & \multicolumn{2}{|l|}{ Não evidente. } \\
\hline \multirow[b]{2}{*}{ Participação } & Tipo & Cooperação & Humor & Linguagem \\
\hline & $\begin{array}{l}\text { Interação entre crianças; } \\
\text { responde diferentemente } \\
\text { para crianças e adultos. }\end{array}$ & $\begin{array}{l}\text { Inicia mais jogos do que } \\
\text { entra em jogos de outros; } \\
\text { mostra e dá objetos. }\end{array}$ & $\begin{array}{l}\text { Sorri; ri de jogos } \\
\text { físicos e em } \\
\text { antecipação. }\end{array}$ & $\begin{array}{l}\text { Gestos com intenção de comunicar-se; } \\
\text { esponde a palavras familiares e } \\
\text { expressões faciais; responde a questões. }\end{array}$ \\
\hline
\end{tabular}


Tabela 3

Versão Brasileira da Escala Lúdica Pré-Escolar de Knox - Revisada para Avaliação de Crianças de 12 a 18 Meses de Idade

\begin{tabular}{|c|c|c|c|c|}
\hline \multirow[b]{2}{*}{$\begin{array}{l}\text { Domínio } \\
\text { Espacial }\end{array}$} & \multicolumn{2}{|c|}{ Coordenação Motora Grossa } & \multicolumn{2}{|r|}{ Interesse } \\
\hline & \multicolumn{2}{|c|}{$\begin{array}{l}\text { Fica em pé sem apoio; senta; curva-se e recupera o } \\
\text { equilíbrio; anda com a base alargada; faz } \\
\text { movimentos amplos envolvendo grandes grupos } \\
\text { musculares; lança bolas. }\end{array}$} & \multicolumn{2}{|c|}{$\begin{array}{l}\text { Pratica padrões de movimentos básicos; experiências no movimento; } \\
\text { explora várias sensações cinestésicas e proprioceptivas; movimenta } \\
\text { objetos (ex. bolas, carrinhos, brinquedos de puxar). }\end{array}$} \\
\hline & Manipulação & Construção & Objetivo & Atenção \\
\hline $\begin{array}{l}\text { Domínio } \\
\text { Material }\end{array}$ & $\begin{array}{l}\text { Arremessa; encaixa; } \\
\text { puxa; carrega; gira; } \\
\text { abre; fecha. }\end{array}$ & $\begin{array}{l}\text { Empilha; desmonta; junta; } \\
\text { despende pequeno esfor- } \\
\text { ço para obter resultados; } \\
\text { relaciona adequadamente } \\
\text { dois objetos (ex.: tampa e } \\
\text { panela). }\end{array}$ & $\begin{array}{l}\text { Variedade de } \\
\text { esquemas; } \\
\text { importância do } \\
\text { processo; tentativa e } \\
\text { erro; brincar } \\
\text { relacional. }\end{array}$ & Troca rapidamente de atividade. \\
\hline \multirow[b]{2}{*}{$\begin{array}{l}\text { "Faz de conta" I } \\
\text { Jogo Simbólico }\end{array}$} & \multicolumn{2}{|c|}{ Imitação } & \multicolumn{2}{|r|}{ Dramatização } \\
\hline & \multicolumn{2}{|c|}{$\begin{array}{l}\text { De ações simples; eventos atuais e adultos; imita } \\
\text { novos movimentos; compõe esquemas simples (ex.: } \\
\text { coloca a boneca em um carro e empurra). }\end{array}$} & \multicolumn{2}{|c|}{$\begin{array}{l}\text { Começa o "faz de conta" utilizando a si próprio (ex.: se alimenta com } \\
\text { uma colher); "faz de conta" com objetos animados e inanimados. }\end{array}$} \\
\hline \multirow[b]{2}{*}{ Participação } & Tipo & Cooperação & Humor & Linguagem \\
\hline & $\begin{array}{l}\text { Pode ser solitário ou } \\
\text { observador; começa a } \\
\text { interação com pares. }\end{array}$ & $\begin{array}{l}\text { Procura conseguir } \\
\text { atenção; pede brinquedos; } \\
\text { aponta; mostra; oferece } \\
\text { brinquedos, mas é ainda } \\
\text { um tanto possessivo; } \\
\text { persistente. }\end{array}$ & $\begin{array}{l}\text { Ri de eventos } \\
\text { incompatíveis. }\end{array}$ & $\begin{array}{l}\text { Diz frases sem sentido enquanto brinca } \\
\text { sozinho; usa gestos e palavras para } \\
\text { comunicar desejos; nomeia objetos; } \\
\text { cumprimenta outros; responde pedidos } \\
\text { simples; provoca; exclama; protesta; } \\
\text { combina palavras e gestos. }\end{array}$ \\
\hline
\end{tabular}

Tabela 4

Versão Brasileira da Escala Lúdica Pré-Escolar de Knox - Revisada para Avaliação de Crianças de 18 a 24 Meses de Idade

\begin{tabular}{|c|c|c|c|c|}
\hline \multirow[b]{2}{*}{$\begin{array}{l}\text { Domínio } \\
\text { Espacial }\end{array}$} & \multicolumn{2}{|c|}{ Coordenação Motora Grossa } & \multicolumn{2}{|r|}{ Interesse } \\
\hline & \multicolumn{2}{|c|}{$\begin{array}{l}\text { Corre; agacha; sobe e desce de cadeiras; sobe e } \\
\text { desce escadas (sempre com o mesmo pé para } \\
\text { mudar de degrau); chuta bolas; dirige carros infantis. }\end{array}$} & \multicolumn{2}{|c|}{ Tem em vista o final; divide a tarefa em partes. } \\
\hline \multirow[b]{2}{*}{$\begin{array}{l}\text { Domínio } \\
\text { Material }\end{array}$} & Manipulação & Construção & Objetivo & Atenção \\
\hline & $\begin{array}{l}\text { Coloca em } \\
\text { funcionamento } \\
\text { brinquedos } \\
\text { eletrônicos; } \\
\text { desmancha colar de } \\
\text { contas; faz colar de } \\
\text { contas. }\end{array}$ & $\begin{array}{l}\text { Utiliza instrumentos } \\
\text { (recursos). }\end{array}$ & Prevê antes de agir. & Brinca. \\
\hline \multirow[b]{2}{*}{$\begin{array}{l}\text { "Faz de conta" I } \\
\text { Jogo Simbólico }\end{array}$} & \multicolumn{2}{|c|}{ Imitação } & \multicolumn{2}{|r|}{ Dramatização } \\
\hline & \multicolumn{2}{|c|}{$\begin{array}{l}\text { representaTivo; reconhece meios de utilizar } \\
\text { brinquedos em imitações; imita após a ação }\end{array}$} & \multicolumn{2}{|c|}{$\begin{array}{l}\text { Utiliza bonecas (ex.: trocar de roupa, pentear cabelos); "faz de conta" } \\
\text { utilizando mais de um objeto ou pessoa; combina duas ou mais ações } \\
\text { no "faz de conta"; objetos imaginários. }\end{array}$} \\
\hline & Tipo & Cooperação & Humor & Linguagem \\
\hline Participação & $\begin{array}{l}\text { Observador; ações } \\
\text { simples e respostas } \\
\text { casuais entre os } \\
\text { pares. }\end{array}$ & $\begin{array}{l}\text { Jogos mais complexos } \\
\text { com vários adultos } \\
\text { (esconde-esconde, pega- } \\
\text { pega); comanda outros } \\
\text { para realizar tarefas. }\end{array}$ & $\begin{array}{l}\text { Ri da designação } \\
\text { incompatível de objetos } \\
\text { e eventos. }\end{array}$ & $\begin{array}{l}\text { Compreende palavras de ação (verbos); } \\
\text { faz perguntas; refere-se a pessoas e } \\
\text { objetos não presentes; combina várias } \\
\text { palavras (faz frases). }\end{array}$ \\
\hline
\end{tabular}


Tabela 5

Versão Brasileira da Escala Lúdica Pré-Escolar de Knox - Revisada para Avaliação de Crianças de 24 a 30 Meses de Idade

\begin{tabular}{|c|c|c|c|c|}
\hline \multirow[b]{2}{*}{$\begin{array}{l}\text { Domínio } \\
\text { Espacial }\end{array}$} & \multicolumn{2}{|c|}{ Coordenação Motora Grossa } & \multicolumn{2}{|r|}{ Interesse } \\
\hline & \multicolumn{2}{|c|}{$\begin{array}{l}\text { Começa a integrar o corpo todo nas atividades - } \\
\text { concentra-se em movimentos complexos; salta no chão; } \\
\text { fica em um pé só brevemente; joga (parado) uma bola } \\
\text { sem deixar cair. }\end{array}$} & \multicolumn{2}{|c|}{ Explora novos modelos de movimentos (ex.: pulos); faz bagunça. } \\
\hline & Manipulação & Construção & Objetivo & Atenção \\
\hline $\begin{array}{l}\text { Domínio } \\
\text { Material }\end{array}$ & $\begin{array}{l}\text { Experimenta; apalpa; } \\
\text { aperta; esvazia; enche. }\end{array}$ & $\begin{array}{l}\text { Rabisca; faz colar de } \\
\text { contas; monta quebra- } \\
\text { cabeças de } 4 \text { ou } 5 \text { peças; } \\
\text { constrói horizontal e } \\
\text { verticalmente. }\end{array}$ & $\begin{array}{l}\text { O processo é } \\
\text { importante - menor } \\
\text { interesse no produto } \\
\text { final (ex.: rabisca, } \\
\text { aperta); planeja } \\
\text { ações. }\end{array}$ & $\begin{array}{l}\text { Interesse intenso; brinca quieto durante } \\
\text { mais de } 15 \text { min.; brinca com um único } \\
\text { objeto ou tema durante } 5 \text { a } 10 \text { min. }\end{array}$ \\
\hline \multirow[b]{2}{*}{$\begin{array}{l}\text { "Faz de conta" I } \\
\text { Jogo Simbólico }\end{array}$} & \multicolumn{2}{|c|}{ Imitação } & \multicolumn{2}{|r|}{ Dramatização } \\
\hline & \multicolumn{2}{|c|}{$\begin{array}{l}\text { Da rotina dos adultos utilizando-se de brinquedos - } \\
\text { imitação dos parentes (ex.: criança alimentando a } \\
\text { boneca); imita seus pares; brincar representativo. }\end{array}$} & \multicolumn{2}{|c|}{$\begin{array}{l}\text { Personifica bonecas e animais; tem amigos imaginários; } \\
\text { representa sozinho; elabora eventos diários com detalhes. }\end{array}$} \\
\hline & Tipo & Cooperação & Humor & Linguagem \\
\hline Participação & $\begin{array}{l}\text { Paralelo (brinca ao lado de } \\
\text { outras crianças, porém } \\
\text { seu brincar ainda é } \\
\text { independente); aproveita a } \\
\text { presença de outros; é } \\
\text { tímido na presença de } \\
\text { estranhos. }\end{array}$ & $\begin{array}{l}\text { Possessivo; tira à força } \\
\text { brinquedos de outras } \\
\text { crianças; amontoa; não } \\
\text { divide; resiste se Ihe tiram } \\
\text { o brinquedo; brinca } \\
\text { independente; inicia a } \\
\text { própria. }\end{array}$ & $\begin{array}{l}\text { Ri de combinações } \\
\text { simples entre eventos } \\
\text { incompatíveis e uso } \\
\text { de palavras. }\end{array}$ & $\begin{array}{l}\text { Falante; muito poucas palavras sem } \\
\text { sentido; começa a utilizar palavras para } \\
\text { comunicar ideias, informações, } \\
\text { questões, comentários ou atividades. }\end{array}$ \\
\hline
\end{tabular}

Tabela 6

Versão Brasileira da Escala Lúdica Pré-Escolar de Knox - Revisada para Avaliação de Crianças de 30 a 36 Meses de Idade

\begin{tabular}{|c|c|c|c|c|}
\hline \multirow[b]{2}{*}{$\begin{array}{l}\text { Domínio } \\
\text { Espacial }\end{array}$} & \multicolumn{2}{|c|}{ Coordenação Motora Grossa } & \multicolumn{2}{|r|}{ Interesse } \\
\hline & \multicolumn{2}{|c|}{$\begin{array}{l}\text { Corre desviando de obstáculos; faz curvas; sobe em } \\
\text { móveis; sobe e desce escadas (alternado os pés); pega } \\
\text { a bola no ar; fica nas pontas dos pés. }\end{array}$} & Brincar desorganiza & \\
\hline \multirow[b]{2}{*}{$\begin{array}{l}\text { Domínio } \\
\text { Material }\end{array}$} & Manipulação & Construção & Objetivo & Atenção \\
\hline & Combina; compara. & Múltiplas combinações. & $\begin{array}{l}\text { Brinquedos com } \\
\text { partes móveis (ex.: } \\
\text { caminhões com } \\
\text { caçamba, bonecas } \\
\text { com articulações). }\end{array}$ & 15 a $30 \mathrm{~min}$. \\
\hline \multirow[b]{2}{*}{$\begin{array}{l}\text { "Faz de conta" I } \\
\text { Jogo Simbólico }\end{array}$} & & itação & \multicolumn{2}{|r|}{ Dramatização } \\
\hline & \multicolumn{2}{|c|}{$\begin{array}{l}\text { Brinquedos como agentes (ex.: boneca se alimentando), } \\
\text { representação mais abstrata dos objetos; múltiplas } \\
\text { combinações (ex.: alimenta a boneca, coloca-a na } \\
\text { cama). }\end{array}$} & \multicolumn{2}{|c|}{$\begin{array}{l}\text { Desenvolve sequência de ações (ex.: mexe, bate e serve um } \\
\text { bolo). }\end{array}$} \\
\hline & Tipo & Cooperação & Humor & Linguagem \\
\hline Participação & $\begin{array}{l}\text { Paralelo; inicia o brincar } \\
\text { associativo com } 2 \text { ou } 3 \\
\text { crianças; brinca em } \\
\text { companhia durante } 1 \text { a } 2 \\
\text { horas. }\end{array}$ & $\begin{array}{l}\text { Entende as necessidades } \\
\text { de outros. }\end{array}$ & $\begin{array}{l}\text { Ri de combinações } \\
\text { complexas entre } \\
\text { eventos e palavras. }\end{array}$ & $\begin{array}{l}\text { Faz perguntas (quem, quando, qual, } \\
\text { onde, por que); relaciona eventos em } \\
\text { ordem temporal. }\end{array}$ \\
\hline
\end{tabular}


Tabela 7

Versão Brasileira da Escala Lúdica Pré-Escolar de Knox - Revisada para Avaliação de Crianças de 36 a 48 Meses de Idade

\begin{tabular}{|c|c|c|c|c|}
\hline \multirow[b]{2}{*}{$\begin{array}{l}\text { Domínio } \\
\text { Espacial }\end{array}$} & \multicolumn{2}{|c|}{ Coordenação Motora Grossa } & \multicolumn{2}{|r|}{ Interesse } \\
\hline & \multicolumn{2}{|c|}{$\begin{array}{l}\text { Maior coordenação dos movimentos corporais; anda deslizando } \\
\text { os pés no chão, pulando, escalando e correndo; acelera; } \\
\text { desacelera; pula com um pé só } 3 \text { a } 5 \text { vezes; salta com um pé só; } \\
\text { pega a bola no ar; joga a bola usando ombro e cotovelo; pula } \\
\text { distâncias maiores. }\end{array}$} & \multicolumn{2}{|c|}{$\begin{array}{l}\text { Qualquer coisa nova; manipulação motora fina de } \\
\text { materiais; se auto desafia com tarefas difíceis. }\end{array}$} \\
\hline \multirow[b]{2}{*}{ Domínio Material } & Manipulação & Construção & Objetivo & Atenção \\
\hline & $\begin{array}{l}\text { Atividades que envolvem } \\
\text { pequenos grupos } \\
\text { musculares - martela, } \\
\text { seleciona pequenos objetos, } \\
\text { encaixa pequenos objetos, } \\
\text { recorta. }\end{array}$ & $\begin{array}{l}\text { tém produtos simples; } \\
\text { nbina materiais para } \\
\text { ncadeiras; separa; constrói em } \\
\text { s dimensões; planejamento } \\
\text { dente. }\end{array}$ & $\begin{array}{l}\text { Começa a } \\
\text { demonstrar } \\
\text { interesse em } \\
\text { produtos já } \\
\text { acabados. }\end{array}$ & $\begin{array}{l}\text { Passa } 30 \text { min. no mesmo local; } \\
\text { brinca com um único objeto ou } \\
\text { alguns por } 10 \text { min. }\end{array}$ \\
\hline \multirow[t]{2}{*}{$\begin{array}{l}\text { "Faz de conta" / } \\
\text { Jogo Simbólico }\end{array}$} & \multicolumn{2}{|c|}{$\begin{array}{l}\text { Imitações mais complexas do mundo real, com ênfase nas } \\
\text { atividades domésticas e animais; simbólica; lembra experiências } \\
\text { passadas. }\end{array}$} & \multicolumn{2}{|c|}{$\begin{array}{l}\text { Roteiros complexos para sequências de "faz de conta" já } \\
\text { em progresso; sequências de histórias; "faz de conta" } \\
\text { com reprodução de brinquedos; utiliza um brinquedo } \\
\text { para representar outro; representa múltiplas } \\
\text { personalidades com sentimentos (principalmente irritada } \\
\text { e chorando); pequeno interesse em fantasias; caracteres } \\
\text { imaginários. }\end{array}$} \\
\hline & Tipo & Cooperação & Humor & Linguagem \\
\hline Participação & $\begin{array}{l}\text { BRINCAR associativo; sem } \\
\text { organização para alcançar um } \\
\text { objetivo comum; maior interesse } \\
\text { nos pares do que nas atividades; } \\
\text { aproveita a companhia de outros; } \\
\text { inicia o brincar cooperativo; } \\
\text { forma grupos. }\end{array}$ & $\begin{array}{l}\text { limitada; às vezes se } \\
\text { revezam em uma tarefa; } \\
\text { pede ao invés de tomar } \\
\text { objetos à força; pequeno } \\
\text { esforço para controlar os } \\
\text { outros; se separa facilmente; } \\
\text { junta-se a outros nas } \\
\text { brincadeiras. }\end{array}$ & $\begin{array}{l}\text { Ri de } \\
\text { palavras sem } \\
\text { sentido; faz } \\
\text { rimas. }\end{array}$ & $\begin{array}{l}\text { Utiliza palavras para comunicar-se com } \\
\text { seus pares; tem interesse em novas } \\
\text { palavras; canta canções simples; usa } \\
\text { um vocabulário descritivo; muda o } \\
\text { discurso dependendo do ouvinte. }\end{array}$ \\
\hline
\end{tabular}


Tabela 8

Versão Brasileira da Escala Lúdica Pré-Escolar de Knox - Revisada para Avaliação de Crianças de 48 a 60 Meses de Idade

Coordenação Motora Grossa

Nível aumentado de atividades; consegue se concentrar no

Domínio objetivo em vez do movimento; realiza as atividades

Espacial motoras grossas com tranquilidade (sem esforço); para de repente; testa sua força (resistência); exagera os movimentos; escala; galopa; sobe em escadas; pega bola no ar com os cotovelos para o lado.

\begin{tabular}{|c|c|c|c|c|}
\hline \multirow[b]{2}{*}{ Domínio Material } & Manipulação & Construção & Objetivo & Atenção \\
\hline & $\begin{array}{l}\text { Controle motor fino } \\
\text { aumentado; } \\
\text { movimentos rápidos; } \\
\text { força; puxa com força. }\end{array}$ & $\begin{array}{l}\text { tém produtos; planejamento } \\
\text { pecífico evidente; constrói } \\
\text { truturas complexas; monta } \\
\text { ebra-cabeças de } 10 \text { peças. }\end{array}$ & $\begin{array}{l}\text { O produto é muito } \\
\text { importante e usado para que } \\
\text { a criança se expresse; } \\
\text { exagera. }\end{array}$ & $\begin{array}{l}\text { Se entretém mais de uma } \\
\text { hora; brinca com um único } \\
\text { objeto ou tema durante } 10 \text { ou } \\
15 \text { min. }\end{array}$ \\
\hline \multirow{3}{*}{$\begin{array}{l}\text { "Faz de conta" I } \\
\text { Jogo Simbólico }\end{array}$} & \multicolumn{2}{|c|}{ Imitação } & \multicolumn{2}{|c|}{ Dramatização } \\
\hline & \multicolumn{2}{|c|}{$\begin{array}{l}\text { Incorpora novos roteiros dos adultos (ex.: roupas } \\
\text { utilizadas); a realidade é importante. }\end{array}$} & \multicolumn{2}{|c|}{$\begin{array}{l}\text { Utiliza o conhecimento que já lhe é familiar para construir uma } \\
\text { nova situação (ex.: expandindo o tema de uma história ou } \\
\text { programa de TV); função ("cargo") nas brincadeiras para ou } \\
\text { com os outros; atua com emoções mais complexas; as } \\
\text { histórias têm sequências; temas do doméstico para o } \\
\text { fantástico; se diverte com fantasias; gosta de se exibir. }\end{array}$} \\
\hline & Tipo & Cooperação & Humor & Linguagem \\
\hline Participação & $\begin{array}{l}\text { Cooperativo; grupos de } 2 \\
\text { a } 3 \text { organizados para } \\
\text { atingir um objetivo; prefere } \\
\text { brincar com outros a } \\
\text { brincar sozinho; grupos de } \\
\text { brincadeiras com regras } \\
\text { simples. }\end{array}$ & $\begin{array}{l}\text { Revezam-se em "turnos"; } \\
\text { tenta controlar as atividades } \\
\text { dos outros; é autoritário; } \\
\text { forte sentimento de família e } \\
\text { lar; considera parentes como } \\
\text { autoridades. }\end{array}$ & $\begin{array}{l}\text { Distorções do que lhe é } \\
\text { conhecido. }\end{array}$ & $\begin{array}{l}\text { Brinca com as palavras; } \\
\text { inventa; desenvolve narrativas } \\
\text { longas; pergunta } \\
\text { insistentemente; se comunica } \\
\text { com os pares para organizar } \\
\text { atividades; faz ameaças e } \\
\text { brincadeiras engraçadas; } \\
\text { canta músicas inteiras; utiliza a } \\
\text { linguagem para expressar } \\
\text { funções, pensamento e } \\
\text { raciocínio verbal. }\end{array}$ \\
\hline
\end{tabular}

Orgulha-se no desempenho das atividades (ex.: mostra e fala sobre seus produtos; compara com outros colegas; gosta de seus desenhos serem expostos); ideias complexas; brincar desorganizado.
Interesse raciocínio verbal. 
Tabela 9

Versão Brasileira da Escala Lúdica Pré-Escolar de Knox - Revisada para Avaliação de Crianças de 60 a 72 Meses de Idade

\section{Coordenação Motora Grossa}

Domínio Mais sereno; bom controle muscular e equilíbrio; pula com

Espacial um pé só mais de 5 vezes; pula tendo uma base estreita; salta para pegar a bola no ar; salta; dá cambalhotas; patina; pula estando agachado no chão.

\begin{tabular}{|c|c|c|c|c|}
\hline \multirow[b]{2}{*}{ Domínio Material } & Manipulação & Construção & Objetivo & Atenção \\
\hline & $\begin{array}{l}\text { Usa ferramentas para } \\
\text { fazer as coisas; copia; } \\
\text { traça; combina materiais. }\end{array}$ & $\begin{array}{l}\text { Obtém produtos } \\
\text { reconheciveis; gosta de } \\
\text { pequenas construções; } \\
\text { atenta para os detalhes; } \\
\text { utiliza seus produtos nas } \\
\text { brincadeiras. }\end{array}$ & Replicar a realidade. & $\begin{array}{l}\text { Brinca com um único objeto ou } \\
\text { tema por } 15 \text { min. ou mais. }\end{array}$ \\
\hline \multirow[b]{2}{*}{$\begin{array}{l}\text { "Faz de conta" / } \\
\text { Jogo Simbólico }\end{array}$} & \multicolumn{2}{|c|}{ Imitação } & \multicolumn{2}{|c|}{ Dramatização } \\
\hline & \multicolumn{2}{|c|}{$\begin{array}{l}\text { Continua a construir novos temas com ênfase na realidade } \\
\text { - reconstrução do mundo real. }\end{array}$} & \multicolumn{2}{|c|}{$\begin{array}{l}\text { Histórias com sequências; as fantasias são importantes; utiliza } \\
\text { acessórios e fantoches; dirige as ações de três bonecas - } \\
\text { fazendo com que interajam; organiza outra criança e } \\
\text { acessórios para cada função no brincar. }\end{array}$} \\
\hline & Tipo & Cooperação & Humor & Linguagem \\
\hline Participação & $\begin{array}{l}\text { Grupos cooperativos de } 3 \\
\text { a 6; organização de jogos } \\
\text { mais complexos e } \\
\text { representações } \\
\text { dramáticas; jogos } \\
\text { competitivos; entende as } \\
\text { regras de um jogo justo. }\end{array}$ & $\begin{array}{l}\text { Compromisso com a } \\
\text { facilitação das brincadeiras; } \\
\text { rivalidade nos jogos } \\
\text { competitivos; jogos com } \\
\text { regras; brincar colaborativo } \\
\text { quando são coordenadas } \\
\text { funções e temas são } \\
\text { direcionados para um } \\
\text { objetivo. }\end{array}$ & $\begin{array}{l}\text { Ri dos múltiplos significados } \\
\text { de cada palavra. }\end{array}$ & $\begin{array}{l}\text { Importante no brincar } \\
\text { sociodramático; usa palavras } \\
\text { como parte das brincadeiras } \\
\text { tão bem quanto as organiza; } \\
\text { interesse no presente; } \\
\text { conversa como adulto; utiliza } \\
\text { termos relacionais; canta e } \\
\text { dança de acordo com o } \\
\text { significado das músicas. }\end{array}$ \\
\hline
\end{tabular}

\section{Interesse}

Na realidade - manipulação de situações da vida real, fazendo algo útil; permanência do produto; brinquedos que "realmente funcionem". objetivo.
A partir da pontuação obtida nas avaliações das filmagens realizadas pelas duas examinadoras, foi realizada a análise estatística utilizando-se o teste de Spearman, que encontrou um alto coeficiente de cor- relação intraexaminador em todas as dimensões da escala, indicando, portanto, concordância entre as duas avaliações, como pode ser visto na Tabela 10.

Tabela 10

Coeficientes de Correlação de Spearman e Niveis de Significância Intraexaminadoras

\begin{tabular}{ccccc}
\hline \multirow{2}{*}{ Dimensão } & \multicolumn{2}{c}{ Examinadora 1 } & \multicolumn{2}{c}{ Examinadora 2 } \\
\cline { 2 - 5 } & Coef. de Correlação & Nível de Significância & Coef. de Correlação & Nível de Significância \\
\hline Domínio espacial & 0,94 & 0,0002 & 1,00 & 0,0000 \\
Domínio material & 0,93 & 0,0003 & 0,99 & 0,0000 \\
"Faz de conta" / Jogo Simbólico & 0,87 & 0,0024 & 0,99 & 0,0000 \\
Participação & 0,94 & 0,0000 & 1,00 & 0,0000 \\
\hline Todos & 0,97 & 0,0000 & 0,99 & 0,0000 \\
\hline
\end{tabular}

Em ambas as análises interexaminadoras, ainda utilizando-se o teste de Spearman, foram encontrados altos coeficientes de correlação, todos significantes (Tabela 11), o que sugere que, embora existam peque- nas diferenças entre as avaliadoras, estas não invalidam a consistência e repetibilidade do instrumento de avaliação. 
Tabela 11

Coeficientes de Correlação de Spearman e Níveis de Significância Interexaminadoras

\begin{tabular}{ccccc}
\hline \multirow{2}{*}{ Dimensão } & \multicolumn{2}{c}{ Primeira Avaliação } & \multicolumn{2}{c}{ Segunda Avaliação } \\
\cline { 2 - 5 } & Coef. de Correlação & Nível de Significância & Coef. de Correlação & Nível de Significância \\
\hline Domínio espacial & 0,91 & 0,0008 & 0,94 & 0,0002 \\
Domínio material & 0,93 & 0,0003 & 0,99 & 0,0000 \\
"Faz de conta" / Jogo Simbólico & 0,78 & 0,0126 & 0,95 & 0,0001 \\
Participação & 0,92 & 0,0004 & 0,92 & 0,0004 \\
\hline Todos & 0,92 & 0,0000 & 0,95 & 0,0000 \\
\hline
\end{tabular}

\section{DISCUSSÃO}

Este trabalho apresentou a versão traduzida e culturalmente adaptada da Escala Lúdica Pré-Escolar de Knox - Revisada, para uso na população brasileira. Acredita-se que os cuidados tomados durante todo o processo de adaptação transcultural garantiram a equivalência semântica (significado das palavras), idiomática (expressões e coloquialismos), de experiências (ações e tarefas esperadas dos indivíduos avaliados pela escala) e conceitual (interpretação dos conceitos apresentados) entre a versão original e esta brasileira, conforme o indicado por Beaton e cols. (2000).

Os resultados da análise estatística deste estudo são condizentes com os estudos realizados por Bledsoe e Sheperd (1982) e por Harrison e Kielhofner (1986), os quais se propuseram a avaliar a confiabilidade e validade da Escala Lúdica Pré-Escolar, ainda em sua versão não revisada. Os coeficientes de correlação e os respectivos níveis de significância, tanto intraexaminadores quanto interexaminadores apontam para a confiabilidade, consistência e repetibilidade da versão brasileira da Escala Lúdica Pré-Escolar de Knox - Revisada.

A partir do processo de adaptação transcultural da Escala Lúdica Pré-Escolar de Knox - Revisada, alguns estudos foram desenvolvidos e demonstram a aplicabilidade junto a diferentes populações, tais como crianças com Síndrome de Down (Solai \& Pfeifer, 2007); hospitalizadas com condições crônicas (Grigolatto \& Pfeifer, 2007); em situação de vulnerabilidade social (Maninni \& Pfeifer, 2009); com paralisia cerebral (Pfeifer, Pereira, Silva \& Panúncio-Pinto, 2011) e com histórico de prematuridade (Rombe, 2012). Desta forma, este estudo contribui para a área de conhecimento do brincar e possibilita posteriores utilizações do instrumento, já traduzido e adaptado, em trabalhos de avaliação e comparação de diferentes populações de crianças pré-escolares, com ou sem patologias.

\section{REFERÊNCIAS}

Beaton, D. E., Bombardier, C., Guillemin, F., \& Ferraz, M. B. (2000). Guidelines for the process of cross-cultural adaptation of self-report measures. Spine, 25, 3186-3191.

Bledsoe, N. P., \& Shepherd, J. T. (1982). A study of reliability and validity of a preschool play scale. The American Journal of Occupational Therapy, 36, 783-788.

Braccialli, L. M. P., Manzini, E. J. \& Reganhan, W. G. (2004). Contribuição de um programa de jogos e brincadeiras adaptados para a estimulação de habilidades motoras em alunos com deficiência física. Temas Sobre Desenvolvimento, 13, 37-46.

Bundy, A. C. (1989). A comparison of the play skills of normal boys and boys with sensory integrative dysfunction. The Occupational Therapy Journal of Research, 9, 84-100.

Bundy, A. C. (2000). Recreação e entretenimento: O que procurar. Em L. D. Parham \& L. S. Fazio (Eds.), A recreação na terapia ocupacional pediátrica (pp. 52-66). São Paulo: Santos.

Clifford, J. M., \& Bundy, A. C. (1989). Play preference and play performance in normal boys and boys with sensory integrative dysfunction. The Occupational Therapy Journal of Research, 9, 202-217.

Emmel, M. L. G., Oliveira, A. A. E, \& Malfitano, A. P. S. (2000). Brinquedoteca: Um espaço experimental para o desenvolvimento infantil. Revista de Estudos Universitários, 26, 141-156.

Ferland, F. (2006). O Modelo Lúdico: O brincar, a criança com deficiência física e a terapia ocupacional ( $3^{\mathrm{a}}$ ed.). São Paulo: Roca.

Gariépy, N., \& Howe, N. (2003). The therapeutic power of play: Examining the play of young children with leukaemia. Child: Care, Health \& Development, 29, 523-537.

Grigolatto, T., \& Pfeifer, L. I. (2007). Avaliação do comportamento lúdico em crianças portadoras de doenças crônicas hospitalizadas Em Associação dos Terapeutas Ocupacionais de Goiás (Ed.), Anais do X Congresso Brasileiro de Terapia Ocupacional. Goiânia: ATOG.

Harrison, H., \& Kielhofner, G. (1986). Examining reliability and validity of the preschool play scale with handicapped children. The American Journal of Occupational Therapy, 54, 73-82.

Howard, A. C. (1986). Developmental play ages of physically abused and nonabused children. The American Journal of Occupational Therapy, 40, 691-695.

Kielhofner, G., Barris, R., Bauer, D., Shoestock, B. \& Walker, L. (1983). A comparison of play behavior in nonhospitalized and 
hospitalized children. The American Journal of Occupational Therapy, 37, 305-312.

Kishimoto, T. M. (2008). Jogo, brinquedo, brincadeira e a educação (11 ${ }^{\mathrm{a}}$ ed.). São Paulo: Cortez.

Knox, S. H. (1968). Observation and assessment of the everyday play behavior of the mentally retarded child (Dissertação de mestrado). University of Southern California, Los Angeles.

Knox, S. H. (2000). Desenvolvimento e uso corrente da escala lúdica pré-escolar de Knox. Em L. D. Parham \& L. S. Fazio (Eds.), A recreação na terapia ocupacional pediátrica (pp. 3551). São Paulo: Santos.

Knox, S. H. (2002). Avaliação da recreação e lazer. Em M. E. Neistadt \& E. B. Crepeau (Eds.), Willard \& Spackman - Terapia ocupacional (pp. 195-201). Rio de Janeiro: Guanabara Koogan.

Linder, T. W. (2001). Transdisciplinary play-based assessment: A functional approach to working with young children. Baltimore, MD: Brookes.

Maninni, J., \& Pfeifer, L. I. (2009). Desempenho no brincar de crianças pré-escolares que se encontram em situação de vulnerabilidade social: Um estudo da terapia ocupacional. Em Associação Cearense de Terapeutas Ocupacionais (Ed.) Anais do XI Congresso Brasileiro de Terapia Ocupacional. Fortaleza: ACTO.

Messier, J., Ferland, F. \& Majnemer, A. (2008). Play behavior of school age children with intellectual disability: Their capacities, interests and attitude. Journal of Developmental and Physical Disabilities, 20, 193-207.

Morrison, C. D., Bundy, A. C. \& Fisher, A. G. (1991). The contribution of motor skills and playfulness to the play performance of preschoolers. The American Journal of Occupational Therapy, 45, 687-694.

O’Brien, J., Coker, P., Lynn, R., Suppinger, R., Rabon, S., Aubin, M. S., \& Ward, A. T. (2000). The impact of occupational therapy on a child playfulness. Occupational Therapy in Health Care, 12, 39-51.

Pedrosa, A. M., Monteiro, H., Lins, K., Pedrosa, F., \& Melo, C. (2007). Diversão em movimento: Um projeto lúdico para crianças hospitalizadas no Serviço de Oncologia Pediátrica do Instituto Materno Infantil Prof. Fernando Figueira, IMIP. Revista Brasileira de Saúde Materno-Infantil, 7, 99-106.

Pereira, E. T. (2005). Brincar e criança. Em A. Carvalho, F. Salles, M. Guimarães \& J. A. Debortoli (Eds.), Brincar(es) (pp.17-27). Belo Horizonte: Editora UFMG.

Pfeifer, L. I. (2006). Estudo preliminar para adequação e validação da Escala Lúdica Pré-Escolar de Knox - Revisada. Manuscrito não-publicado, Faculdade de Medicina de Ribeirão Preto.

Pfeifer, L. I., \& Cruz, D. M. C. (2008). Avaliações do brincar e suas evidências para a prática do terapeuta ocupacional no campo da educação especial. Em M. A. Almeida, E. G. Mendes \& M. C. P. I. Hayashi (Eds.), Temas em educação especial: Múltiplos olhares (pp. 403-412). São Carlos: UFSCar.

Pfeifer, L. I., Pereira, L. C. R. S., Silva, D. B. R., \& PanúncioPinto, M. P. (2011). Habilidades de desempenho no brincar de crianças com paralisia cerebral. Arquivos Brasileiros de Paralisia Cerebral, 5, 4-11.

Pfeifer, L. I., Queiroz, M. A., Santos, J. L. F., \& Stagnitti, K. E. (2011). Cross-cultural adaptation and reliability of Child-
Initiated Pretend Play Assessment (ChIPPA). Canadian Journal of Occupational Therapy, 78, 187-195.

Prado, M. S., Braga, L. D. T., Magalhães, L. C., \& Wilson, B. N. (2007). Tradução e adaptação cultural do Developmental Coordination Disorder Questionnaire (DCDQ). Em Associação dos Terapeutas Ocupacionais de Goiás (Org.), Anais do $X$ Congresso Brasileiro de Terapia Ocupacional. Goiânia: ATOG.

Restall, G., \& Magill-Evans, J. (1994). Play and preschool children with autism. The American Journal of Occupational Therapy, 48, 113-120.

Rezende, M. (2005). O brincar sob a perspectiva da terapia ocupacional. Em A. Carvalho, F. Salles, M. Guimarães \& J. A. Debortoli (Eds.), Brincar(es) (pp.51-63). Belo Horizonte: Editora UFMG.

Richardson, P. K. (2001). Use of standardized tests in pediatric practice. Em J. Case-Smith (Ed.), Occupational therapy for children (pp. 246-275). St. Louis, MI: Mosby.

Rombe, P. G. (2012). Comportamento lúdico de crianças de risco e seu desenvolvimento neuropsicomotor (Dissertação de mestrado). Universidade Federal de São Carlos.

Sant'Anna, M. M. M. (2006). Tradução e adaptação transcultural dos protocolos de avaliação do Modelo Lúdico para crianças com paralisia cerebral (Dissertação de mestrado). Universidade Presbiteriana Mackenzie, São Paulo.

Sant'Anna, M. M. M., Blascovi-Assis, S. M. \& Magalhães, L. C. (2008). Adaptação transcultural dos protocolos de avaliação do Modelo Lúdico. Revista de Terapia Ocupacional da Universidade de São Paulo, 19, 34-47.

Schaaf, R. C., \& Mulrooney, L. L. (1989). Occupational therapy in early intervention: A family-centered approach. The American Journal of Occupational Therapy, 43, 745-754.

Sheperd, J. T., Brollier, C. B., \& Dandrow, R. L. (1994). Play skills of preschool children with speech and language delays. Physical \& Occupational Therapy in Pediatrics, 14, 1-20.

Siegel, S., \& Castellan N. J. (2006) Estatística não paramétrica para as ciências do comportamento (S. I. C. Carmona, Trans.). Porto Alegre: Artmed.

Solai, V. Q., \& Pfeifer, L. I. (2007). O envolvimento familiar na estimulação de crianças com síndrome de Down. Em Associação dos Terapeutas Ocupacionais de Goiás (Org.), Anais do X Congresso Brasileiro de Terapia Ocupacional. Goiânia: ATOG.

Stagnitti, K. E. (2007). Child-initiated pretend play assessment (ChIPPA). Manual de aplicação. Melbourne, Australia: CoOrdinates.

Takata, N. (1974). Play as a prescription. Em M. Reilly (Org.), Play as exploratory learning (pp. 209-246). Beverly Hills, CA: Sage.

von Zuben, M. V., Crist, P. A., \& Mayberry, W. (1991). A pilot study of differences in play behavior between children of low and middle socioeconomic status. The American Journal of Occupational Therapy, 45, 113-118.

Recebido: 13/02/2009 Última revisão: 30/05/2012 Aceito: 28/06/2012 